\title{
Cryptocurrencies and Corruption ${ }^{1}$
}

\author{
Petr WAWROSZ - Jan LÁNSKÝ*
}

\begin{abstract}
The paper focuses on the links between cryptocurrencies and corruption. After providing an overview of the literature dealing with the topic, it presents an outline of possible scenarios for how cryptocurrencies can be used in corruption-tainted contracts. The scenarios imply that cryptocurrencies can reduce the costs and risks related to a corruption-tainted contract and make it easier to transfer the corruption-based benefits on an anonymous basis. Their existence also allows corruption-tainted contracts to expand to areas where this did not bring any economic advantages in the past. The paper then explores whether there are any empirical correlations between cryptocurrencies and corruption in different countries. The numbers of Bitcoin automated teller machines (ATM) and cryptocurrency users were used as a proxy for cryptocurrencies and the Corruption Perception Index (CPI) as a proxy for corruption. Although we did not find any clear relationships, we discovered that the largest number of owners or users of cryptocurrencies is in countries with a high prevalence of corruption, but the level of corruption in them did not exceed the critical limit (around the value of 30 points of the CPI index).
\end{abstract}

Keywords: cryptocurrency, cryptoasset, corruption, Bitcoin, Bitcoin ATM, corruption owner or user

JEL Classification: D73, E59

DOI: https://doi.org/10.31577/ekoncas.2021.07.02

\section{Introduction}

Cryptocurrencies are a relatively new phenomenon. The first cryptocurrency was created in 2009 , yet their boom only began after 2015. Inevitably, the scientific literature dealing with this matter is thus also new. Although it is experiencing

* Petr WAWROSZ - Jan LÁNSKÝ, University of Finance and Administration, Estonská 500, 10001 Prague 10, Czech Republic; e-mail: wawrosz.petr@mail.vsfs.cz; lansky@ mail.vsfs.cz

${ }^{1}$ The result was created in solving the student project Intercultural communication: the research on the concept of cultural intelligence $(C Q)$ using objective oriented support for specific university research of the University of Finance and Administration, Prague, the Czech Republic. 
relatively tumultuous growth (for instance, there were around 3200 articles about cryptocurrencies in scholarly journals recorded in the Proquest database till middle of May 2021, of which about 1900 have been published after December 2018), the research performed thus far does not sufficiently address all issues related to the challenges posed by cryptocurrencies. These include the link between cryptocurrencies and corruption. This paper aims at bridging that gap, at least partially. It focuses on how cryptocurrencies can be used for corruption contracts and whether it is possible to establish a correlation or, if appropriate, causality between the level of corruption and the extent to which cryptocurrencies are used in different countries.

For the purposes of the paper, corruption is defined according to Wawrosz (2019, pp. 270 - 271): "any behavior that deviates from generally accepted formal and informal obligations in order to achieve private gain. Corruption is a form of business. On the one hand, there is a subject possessing a certain form of power, whether it be of action or decision. This person is called "the corrupt agent" and can include more than one person (e.g. two or more government officials). The corrupt agent is violating their duties and obligations because they or another subject (e.g. a corrupt relative) has or may benefit from a violation. On the other hand, there is a second subject called "the corrupting agent," who once again can consist of several people (e.g. players of a sport club). The corrupting agent gives or promises to benefit the corrupt agent if the corrupt agent violates their duty. The violation is beneficial for the corrupting agent. By the actions of the corrupt agent, the corrupting agent or some related agent such as a relative may gain some benefits at the expense of a third party that does not participate in corruption."

The paper is structured as follows. The first chapter deals with the substance and ownership of cryptocurrencies. The second chapter presents an overview of literature related to the link between cryptocurrencies and corruption. The third chapter shows how cryptocurrencies can be used in corruption contracts and the consequences of their use. The fourth chapter focus on the empirical correlations between cryptocurrencies and corruption and their possible causalities. The conclusion summarises the key findings.

\section{The Essence and Ownership of Cryptocurrencies}

\subsection{The Essence of Cryptocurrencies}

Cryptocurrencies are decentralised payment systems in which ownership is demonstrated solely through the use of cryptography. The formal definition of cryptocurrencies (Lánsky, 2018a, p. 19) imposes the following six requirements 
on the payment system: 1 . The system reaches consensus on its status on a decentralised basis without the assistance of a central authority. 2. The system keeps an overview record of cryptocurrency units and their ownership. 3. The system defines conditions for how new units come into existence and how their ownership is determined. 4. The ownership of cryptocurrency units is demonstrated solely cryptographically. 5 . The system makes it possible to make transactions to change the ownership of cryptocurrency units. The ownership of these units must be demonstrated to be able to carry out the transaction. 6. If two transactions changing the ownership of the same cryptocurrency units are entered at the same moment, only one of them is realized.

At first, the European Banking Authority (2014, p. 11) classified cryptocurrencies under the category of virtual currencies. A virtual currency is a digital representation of value that is not issued by the central bank and is not linked to the value of the fiat currency but is accepted as a means of currency. Virtual currency can be transferred, deposited, and traded electronically. At present the European Banking Authority (2019, p. 4) classifies cryptocurrencies under the category of cryptoassets. Cryptoassets are a type of private asset that depends primarily on cryptography and distributed ledger technology. Cryptoassets can have payment, investment, and utility functions. They can be subdivided into centralised and decentralised cryptoassets. Cryptocurrencies are decentralised cryptoassets. Centralised cryptoassets include the predecessors of cryptocurrencies, which will be classified in this paper under the more generalised category of centralised digital currencies, given that this is the more established classification.

The design of Bitcoin (Nakamoto, 2008, pp. 2 - 3), the oldest cryptocurrency, was published in October 2008, yet the cryptocurrency itself was not launched until the beginning of January 2009 (Blockchain Luxembourg, 2009). According to the Coinmarketcap (2021), there are currently over 8,000 cryptocurrencies that can be traded on a cryptocurrency stock exchange. Their total market capitalisation exceeds USD 1,500 billion and their daily trading volume is over USD 100 billion. The most important cryptocurrencies by their market capitalisation include Bitcoin, Ethereum, Tether, Binance Coin, Cardano, Polkadot, XRP, Litecoin, and Chainlink (Coinmarketcap, 2021).

Before the emergence of decentralised cryptocurrencies, there was a range of centralised digital currencies in existence. These centralised digital currencies differed from cryptocurrencies in their need to have an operating organisation, called a central authority, which carried out the settlement of transactions. This central authority prevented a double spending attack in which the sender, having one unit of the digital currency at its disposal, would send the same one unit of the digital currency to two different beneficiaries at the same time. Without the 
central authority it would not be possible to determine which of the two transactions is valid (Clark, 2016, p. 17).

The existence of the central authority is the weakest point of a centralised digital currency. A centralised digital currency may come to an end if its central authority faces economic problems (such as DigiCash - for details see e.g. Clark, 2016, p. 11). The central authority may also cease to exist due to the intervention of a state power, examples of which include the centralised digital currencies Liberty Reserve and e-Gold dissolved in this manner in the U.S. (Clark, 2016, p. 20). The implementation of applicable laws or court decisions by the central authority may also be enforced by state power. In this manner, state power can prohibit certain transactions or even seize ownership of a centralised digital currency units from its owners. In cryptocurrency schemes the central authority is replaced with a decentralised anonymous network, thereby eliminating the weakest point of centralised digital currencies. With cryptocurrencies it is not possible to identify the operating organisation, and state power is therefore unable to enforce the implementation of applicable laws or court decisions. Cryptocurrencies provide the certainty of uncensored transactions and make it impossible to seize ownership without the owner's consent.

\subsection{Ownership of Cryptocurrencies}

The ownership of cryptocurrency units is entirely different from the ownership of both tangible and intangible assets. The ownership of cryptocurrency units consists of knowledge of a private key. For any transaction that transfers cryptocurrency units to the benefit of their new owner, it is essential to demonstrate knowledge of the private key corresponding to these units. The private key is a random number, usually consisting of 256 bits. You can imagine this number as a sequence of 256 zeros and ones. The private key is used to create a public key using elliptic-curve cryptography. The public key is then used to generate an address. The address cannot be inverted to identify the public key and the public key likewise cannot be inverted to identify the private key (Antonopoulos, 2017, p. 57). For simplification, we will say that the address is generated from the private key. Where an address is generated from a given private key, this private key will be referred to as the private key corresponding to a given address.

The cryptocurrency units are stored under an address. A person who proves knowledge of the private key corresponding to a given address is entitled to carry out the transaction, i.e. to transfer these units to the benefit of another person. Proof of knowledge of the private key is provided using the cryptographic signature of the transaction intended to transfer the cryptocurrency units. A calculation is performed, but only the person who knows the relevant private key is able 
to complete it. In the proof procedure itself, however, the private key is not disclosed (Antonopoulos, 2017, pp. 139 - 140). If there are cryptocurrency units present under an address, we cannot know whether they have an owner or owners. The private key might not exist, there can be a single copy of the private key, there can be several copies of the private key, or the private key might even be openly published. If there is no transaction carried out to transfer the cryptocurrency units from that address to the benefit of another address, it cannot be determined which of the above options took place. Once a transaction was made, it is possible to exclude the option that there was no copy of the private key; the person who carried out the transaction must have used the private key.

Once a transaction is carried out, there is a person under the old address who can be referred to as the former owner of the cryptocurrency units. Nevertheless, we do not know whether there is an owner of the cryptocurrency units under the new address. Consequently, ownership can only be determined in reference to the past; it is possible to determine that cryptocurrency units had an owner when they are sent. The identity of the person who carried out the transaction cannot be established unless the person takes steps resulting in his or her identification, either knowingly or by negligence. For the reasons described above the ownership of cryptocurrency units is sometimes called Schrödinger's ownership (Lánsky, 2020, p. 56). Until a transaction is made, it is impossible to determine whether there is an owner or who the owner is. Once a transaction is made, it is possible to identify the previous owner but not the new owner. This is analogous to the world of quantum physics and the Schrödinger's cat paradox (Schrödinger, 1935, p. 809). The analogy consists in the impossibility of determining the status (in our case: who is the owner of the cryptocurrency) until a measurement is made (in our case: a transaction).

\section{Literature Review of the Relations between Corruption and Cryptocurrencies}

Most texts dealing with the relationship between cryptocurrencies and corruption focus only on the issue of whether cryptocurrencies can facilitate corruption or, on the contrary, reduce corruption. The authors who believe that cryptocurrencies can serve as means for corruption transactions usually emphasize the anonymity of cryptocurrency users. Lovell (2019) focuses on Bitcoin and notes that it is a quasi-anonymous currency. If a transaction is made in Bitcoins, everyone with access to the blockchain, which plays the role of a public ledger of transactions made, can easily find information about that transaction (information about address of origin, address of destination, amount sent). 
However, the parties to the transaction or the reason for the transaction remain unknown. In addition to the quasi-anonymity of transactions, which can be misused by persons committing crimes, Campbell-Verduyn (2018) points out that the transactions take place in real time and that it is difficult for state authorities to crack down on these transactions in any manner. Dabrowski and Janikowski (2018) note that cryptocurrencies can be used to circumvent various sanctions and restrictions imposed by state authorities. Foley, Karlsen and Putnins (2018) estimated that approximately one-quarter of bitcoin users and one-half of bitcoin transactions are associated with illegal activities. These are not limited to corruption but also include money laundering, tax evasion, illegal acquisition of drugs and weapons, terrorism financing, theft, and fraud (Besharat, 2019; Ciupa, 2019). Albert et al. (2019) analyse how cryptocurrencies facilitate the money laundering process and conclude that corrupt firms and criminal organizations can convert their earnings into cryptocurrencies and then transfer these funds anywhere in the world to evade tax authorities. This increased protection aids the money laundering process because it allows criminal organizations to gain full access to and control over all the revenue they produce. Šimonová, Čentéš and Beléš (2019) emphasize that there is often a lack of regulatory oversight for financial innovations including cryptocurrencies, which means that they often lack a mechanism for clear measurement of risk in their operations.

A number of authors (e.g., Aldaz-Carroll and Aldaz-Carroll, 2018), however, take the opposite view, arguing that cryptocurrencies can reduce corruption. They believe that if a cryptocurrency contains information about all transactions made in the past, it is possible to identify, at least approximately, the different parties to the transactions from the history thereof using current methods (big data analysis) or, where appropriate, it would be possible to create a cryptocurrency where information about the contracting parties is included in the transaction. Konashevych (2017), Sayed and Abbas (2018) are convinced that the decentralised nature of cryptocurrencies could result in decreased governmental regulation or increased liberalisation, where applicable, thus reducing the reasons why people resort to corruption. Similarly, Katona (2018) concludes that blockchain technology will make it possible to eliminate intermediaries and carry out transactions in a transparent manner. This will result in reduced costs, thus rendering useless any corruption aimed at avoiding the costs.

De Souza, Luciano and Wiedenhöft (2018) argue that blockchain can mitigate factors contributing to corruption. The principal-agent theory (e.g., Aidt, 2016) sees corruption as a sign of the principal-agent problem and information asymmetry. Corruption is engaged in by an agent who is hired by the principal to achieve the outcome desired by the principal. While the principal wants the 
agent to always act in the principal's interest, it is difficult for the principal to monitor the agent's activities, which leaves the agents with a certain scope for promoting their own interest, which is contrary to the principal's interest. Many authors (e.g., Klitgaard, 1988; Gong, 2002; Osipian, 2013; Osrecki, 2015) see corruption as a relationship between the agent and another party, in which the agent betrays its principal to receive personal gains. De Souza, Luciano and Wiedenhöft (2018), however, emphasize that blockchain is publicly accessible and that the parties to the contract can have equal access to information, which reduces the information asymmetry, thus making the scope for corruption smaller. Other authors (e.g., Deshwal, Singh Kaurav and Thakur, 2019; Mackey and Cuomo, 2020; Berg, Markey-Towler and Novak, 2020; Sladič et al., 2021) describe different ways how blockchain technology can be used as a tool for transparency and a mean to fight corruption in developing countries - namely, 1. the impossibility of encrypting servers at the same time, which reduces the risk of illegal attack; 2. the ability to detect and prevent fraud in the procurement process; 3 . the fact that smart contracts based on blockchain are self-enforcing - in their pure form (that is, where all triggers and conditions of the contract are managed on-chain) they do not need any external authority to enforce or otherwise manage disputes; and 4. blockchain allows for transactions to be recorded in an immutable and tamper-proof manner.

It is essential to emphasize that the above optimism is not shared by all authors. Ferris (2018) points out that transactions on a blockchain may still be: unauthorized, fraudulent or illegal; executed between related parties; linked to a side agreement that is "off-chain"; or incorrectly classified in the financial statement. Similarly, Nickerson (2019) states that blockchain can only be aware of the inputs, not the reality. The blockchain will track it as valid data, so if you have the authority to input bad data, then the blockchain will validate the bad data. You still have a dependency on real-world, trusted sources of data and authorization. If you corrupt that, then you corrupt the process. Simply put, if those in power still seek to perpetrate frauds, especially those that involve collusion, blockchain may not be a deterrent. Dudley, Pond and Carden (2019) thus offer, in our opinion, a realistic vision emphasizing the fact that cryptocurrencies may reduce corruption, as well as the fact that they can contribute to corruption.

\section{Abuse of Cryptocurrencies in Corruption}

In this chapter, we first present three basic scenarios (S1, S2, and S3) of potential abuse of cryptocurrencies in corruption; see Figure 1. We work with assumptions that a corrupt agent $(\mathrm{X})$ has violated its duties and a corrupting agent 
(Y) benefits from the violation. The cryptocurrencies that $\mathrm{X}$ receives from $\mathrm{Y}$ represent $\mathrm{X}^{\prime} \mathrm{s}$ remuneration for its actions as a corrupt agent. The different scenarios are divided into four stages marked P1, P2, P3, and P4. Some scenarios include only three of the four stages and some stages (in particular P3) differ slightly for each scenario.

Figure 1

\section{Scenarios of Potential Abuse of Cryptocurrencies for Corruption Purposes}

S2, s3 s1, s3

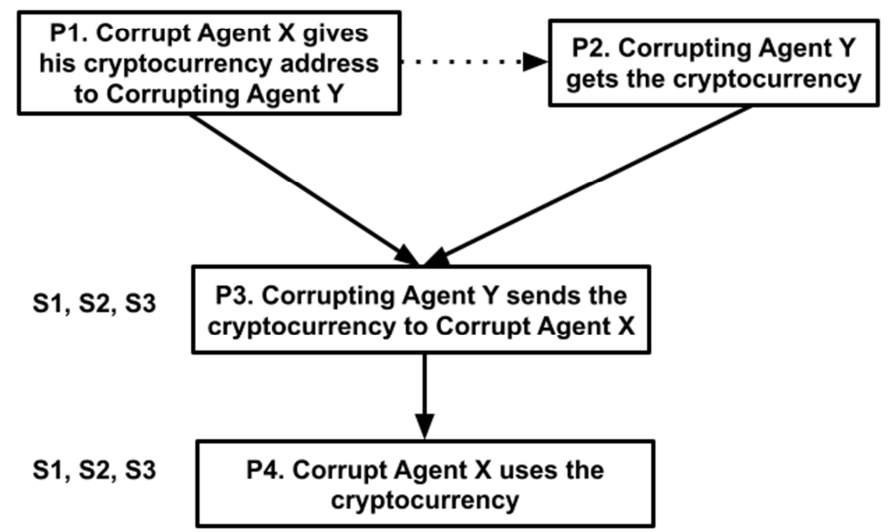

Source: Prepared by the author.

Scenario S1 is an analogy to hiding the cash in a secret location. The corrupting agent (Y) gets hold of an arbitrary cryptocurrency (P2), which she sends in a transaction to a newly created addressed intended for the corrupt agent $(\mathrm{X})$. In the next step, $\mathrm{Y}$ provides $\mathrm{X}$ with the private key to this newly created address (P3). When the private key is handed over (P3), X may not necessarily have any cryptocurrency knowledge whatsoever, and might not even understand what he just received from Y. Moreover, Y may have a copy of the private key in her possession. In such case, if $X$ does not transfer the bribe to the benefit of an address he specifies (P4), Y might be faster and take the bribe back by carrying out a transaction in favour of an address she specifies herself. This is a typical example of Schrödinger's ownership.

Scenario S2 is an analogy to sending a bribe to an anonymous bank account. $\mathrm{X}$ provides $\mathrm{Y}$ with his cryptocurrency address (P1). $\mathrm{Y}$ buys the cryptocurrency and instructs the seller to send it directly to X's cryptocurrency address (P3). $\mathrm{X}$, in turn, can use the cryptocurrency available under his address (P4). 
Scenario S3 assumes that both $\mathrm{X}$ and $\mathrm{Y}$ are familiar with the use of cryptocurrency. $\mathrm{X}$ provides $\mathrm{Y}$ with his cryptocurrency address (P1). If $\mathrm{Y}$ owns the relevant cryptocurrency in the required amount, $\mathrm{P} 2$ is skipped and $\mathrm{Y}$ sends the cryptocurrency straight to X's cryptocurrency address (P3). X can then use the cryptocurrency available under its address (P4).

There are other scenarios requiring advanced user knowledge of cryptocurrencies from both $\mathrm{X}$ and $\mathrm{Y}$. They include using "smart contracts", i.e., a decentralized program carried out in the blockchain of another cryptocurrency (usually Ethereum). For example, $\mathrm{X}$ can use a smart contract to create a new, worthless cryptocurrency and sell its units to $\mathrm{Y}$ who pays to $\mathrm{X}$ for selling. Or the smart contract can be used to run a game of chance in which $Y$ loses a bet against $X$. In both situations, $\mathrm{X}$ receives renumeration that may be related to the violation of its duty that is convenient for Y. But the details of such scenarios are quite difficult for our purposes.

In all scenarios, stage $\mathrm{P} 4$ consists of profit from corruption gained by the corrupt agent. The corrupt agent can have faith in cryptocurrencies and may decide to keep the bribe in the form of the cryptocurrency for a long period of time, e.g., as savings for retirement. If $\mathrm{X}$ safely stores the private key from his address, e.g., by learning it by heart, it can even be impossible to determine whether X's address has an owner, much less whether $\mathrm{X}$ is the owner. For instance, $\mathrm{X}$ might just wish to punish $\mathrm{Y}$ does not wish to derive any gain from the bribe for itself or any other person, so $\mathrm{X}$ has provided $\mathrm{Y}$ with an address for which nobody knows the private key. In general, as long as $\mathrm{X}$, or someone to whom $\mathrm{X}$ reveals his private key, uses the cryptocurrencies that $\mathrm{X}$ received from $\mathrm{Y}$, it will be difficult to prove that $\mathrm{X}$ gained any benefit from his actions violating any of its duties. Revealing X's corruption will thus not be easy.

If $\mathrm{X}$ decides to spend the cryptocurrency, he can do so by converting them to a fiat currency or by purchasing goods. $\mathrm{X}$ will transfer the cryptocurrencies from the current address to the address of the counterparty giving $\mathrm{X}$ the requested fiat currency or goods. This transaction is recorded in the blockchain. At that moment, it is possible to prove that someone had a private key to that address and, thus, derived a benefit from the bribe. However, if a cryptocurrency with a high level of anonymity was used for the bribe, such as Monero, even the blockchain does not make it possible to prove that the transaction was carried out from X's address. Monero anonymises the sender in the transaction using a mechanism called ring signatures (SerHack, 2018, p. 68). Consequently, in such case, it is impossible to prove that $\mathrm{X}$ used the cryptocurrency obtained through corruption, which in turn makes it difficult to expose the corruption. 
$\mathrm{Y}$, when purchasing the cryptocurrency, and $\mathrm{X}$, when selling it (if applicable), can be identified under the Know Your Customer (KYC) procedure, in which the trader must keep the clients' personal data and disclose that data if ordered to do so by state authorities. When using a cryptocurrency with a low level of anonymity, suspicion indicating an interrelation between them can be raised based on the executed transaction stored in the blockchain. But, if a cryptocurrency with a high level of anonymity such as Monero, is used this link is not created in the blockchain; nevertheless, a connection can be demonstrated between the purchasing time of $\mathrm{X}$ and the selling time of $\mathrm{Y}$, and the amount of the cryptocurrency purchased and sold. However, it is essential to emphasize that cryptocurrencies can also be purchased and sold on a fully anonymous basis; for example, at a meeting of cryptocurrency fans. Anonymous exchange is also possible using Bitcoin ATMs, which do not require identification for exchange transactions up to EUR 1,000. Nevertheless, one can also carry out multiple exchange transactions within a period of time or use a number of different Bitcoin ATMs.

The above scenarios imply that cryptocurrencies allow parties to a corruption-tainted contract to transfer a bribe (or more generally, a benefit received by a corrupted agent or a person related to that agent) in a relatively highly anonymous manner. Cryptocurrencies thus extend the possibility for corruption to the situations which, until now, had posed the risk that the bribe would identify the parties to the corruption-tainted contract and expose their corruption behaviour. If fiat money is used as a bribe, handing over such bribe in cash is associated with the risk of loss or the risk that counterfeit bills will be used for the bribe. In bank transfers, it is nowadays relatively easy to identify both the payer and the beneficiary. Other forms of bribes often require a personal meeting between the corrupting agent and the corrupt agent or other persons representing them. Cryptocurrencies reduce those risks at least partially. Although the corrupting agent must still find a suitable person who will violating its duties in favour of the corrupting agent, this search can nowadays take also place online. Consequently, cryptocurrencies together with the online environment reduce the transaction costs of corruption, making contact between the parties to a corruption-tainted contract easier. All of this can result in the expansion of corruption practices.

\section{Empirical Relationships between Cryptocurrencies and Corruption}

\subsection{Bitcoin ATMs or Users and Owners of Cryptocurrencies and Corruption}

In the second chapter, we mentioned that there are two contradictory approaches appearing in the literature thus far as regards the relationship between corruption and cryptocurrencies: 1. Cryptocurrencies can facilitate corruption 
transactions; 2. The technology behind cryptocurrencies results in increased transparency, which reduces the possibilities for corruption behaviour. In this chapter, we focus on whether, for countries with data available, there are any empirical relationships proving either of the above approaches.

It is essential to emphasize that empirical relationships between corruption and cryptocurrencies are difficult to investigate because both corruption and the representation of cryptocurrencies in a certain society are not easy to measure. As regards corruption, the literature (e.g., Rose-Ackerman and Palfika, 2016) mostly shares the view that corruption can be expressed only indirectly since, as a rule, it consists of concealed behaviour. Most commonly, corruption is presented by means of corruption indices, the best known of them being the Corruption Perception Index (CPI) compiled annually by Transparency International. The index ranges from 0 to 100 on the following principle: the higher the value, the less prone to corruption the country is (for details on the index, see for example Lambsdorff, 2007). The index is subject to several objections (see for example Charron, 2016), in particular that it reflects the opinion on how widespread corruption is in the given country, while this opinion may vary significantly from reality. Despite these objections, CPI and other indices are commonly used by scientific literature as a measure of corruption; Campos, Dimova and Saleh (2016) indicate that CPI is used in approximately $40 \%$ of texts examining the relationship between corruption and another variable. We will therefore use this index as a representation of corruption as well.

Given the anonymity of cryptocurrencies, it is not possible to unambiguously identify the countries where the users of cryptocurrencies live. As a result, it can only be determined indirectly whether cryptocurrencies are widespread in a country. One of the easiest ways to obtain a cryptocurrency, which is also anonymous, is to use an automated teller machine (ATM) which can change a fiat currency to a cryptocurrency. The number of such automated teller machines can thus be used as a proxy for the presence of cryptocurrencies - one can presume that the higher the number of those ATMs per inhabitant in a given country, the greater the extent to which cryptocurrencies are used in that country. The current data (from autumn 2019 and autumn 2020) available on the number of automated teller machines in the different countries concern only Bitcoin ATMs per 1 million inhabitants (see Coin ATM Radar, 2019 or 2020); nevertheless, Bitcoin is the most frequently used cryptocurrency (Lánský, 2018b). There is data available for 170 countries and there is at least 1 Bitcoin ATM in approximately 80 countries for both years (there are slight differences for each year). Regardless of the standard objections to their validity (see for example Staddon, 2017), questionnaire surveys may be another source of data on how much cryptocurrencies are 
represented in each country. In 2019 and 2021, two surveys were published (Bucholz, 2019, or 2021) covering 46 (2019) and 55 (2021) countries, in which survey participants were asked if they used or owned cryptocurrencies.

Based on the above data we investigate whether there is a statistically significant relationship for the examined samples between the number of Bitcoin automated teller machines per 1 million inhabitants or the number of users and owners of cryptocurrencies (as proxies for cryptocurrencies, the dependent variable) and corruption represented by CPI. As the CPI value in a single year can be distorted by an incidental fluctuation, an arithmetic average of these index values in the period 2016 - 2018 (for 2019 cryptocurrency data) and 2018 - 2020 (for 2021 cryptocurrency data) were used. These time ranges were chosen because, if both cryptocurrency proxies relate to corruption, the decision whether to install a Bitcoin ATM or to buy a cryptocurrency due to corruption is probably based on longer experience.

The use of cryptocurrencies can be affected by several other factors. The following ones connected with corruption (see for example Rose-Ackerman and Palfika, 2016; Charron, 2016; Mungiu-Pippidi and Heywood, 2020) were used as control variables: GDP per inhabitant in constant prices, inflation, unemployment, gross government debt, and the values of the Doing Business Index and Human Freedom Index (the higher the values of the index, the more favourable the conditions). We created linear regression models for each cryptocurrency proxy where the proxy and all control indicators were independent variables and corruption the independent one. Both models were tested for linearity (by residuals), perfect collinearity (by variance inflation factor), zero expected value, homoscedasticity (by Breusch-Pagan test), and normality (by Shapiro-Wilk test) and they met all conditions. However, the coefficient of determination $\mathrm{R}^{2}$ was low for both dependent variables (for the number of Bitcoin ATMs, 0.22, and for the number of the user or owners of cryptocurrencies, 0.11). None of the variables used is statistically significant and no clear relationship was found between our proxies for cryptocurrencies and corruption. Similarly, there is no significant interaction among any cryptocurrency proxy and any control variable, we did not thus find that corruption affect cryptocurrencies indirectly.

We tested our model in the opposite direction by using CPI as the dependent variable and all other variables, including the number of Bitcoin ATMs or number of users or owners of cryptocurrencies, as the independent ones. The coefficient of determination $\mathrm{R}^{2}$ is 0.87 (the model including the number of Bitcoin ATMs) respectively 0.82 (the model including the number of users or owners of cryptocurrencies), but neither number of Bitcoin ATMs nor the number of users or owners of cryptocurrencies have a statistically significant impact on corruption. 
The main factors affecting CPI in both models are GDP per capita, the Doing Business Index, and the Human Freedom Index, which corresponds to previous studies (for details see for example Mungiu-Pippidi and Heywood, 2020). Using a simple Pearson's correlation coefficient gives a positive correlation of 0.39 between corruption and the numbers of Bitcoin ATMs and a negative correlation of -0.14 between CPI and the number of users or owners of cryptocurrencies. Such values are too low to indicate any clear relationships.

Table 1

Empirical Relationships among Cryptocurrencies and Corruption

\begin{tabular}{|c|c|c|c|c|c|}
\hline \multirow{3}{*}{$\begin{array}{l}\text { Independent } \\
\text { variables } \\
\text { CPI }\end{array}$} & \multicolumn{2}{|c|}{ Dependent variable } & \multirow{3}{*}{\begin{tabular}{l}
\multicolumn{1}{c}{$\begin{array}{c}\text { Independent } \\
\text { variables }\end{array}$} \\
ATM (for fifth \\
column), Users of \\
cryptocurrencies \\
(for sixth column)
\end{tabular}} & \multirow{2}{*}{\multicolumn{2}{|c|}{$\frac{\text { Dependent variable }}{C P I}$}} \\
\hline & \multirow{2}{*}{$\begin{array}{c}A T M \\
-0.073 \\
(0.173)\end{array}$} & \multirow{2}{*}{$\begin{array}{c}\text { Users of } \\
\text { cryptocurrencies } \\
-0.012 \\
(0.074)\end{array}$} & & & \\
\hline & & & & $\begin{array}{l}-0,07345 \\
(0,174)\end{array}$ & $\begin{array}{c}-0,047 \\
(0,278)\end{array}$ \\
\hline GDP & $\begin{array}{c}0.00001 \\
(0.00001)\end{array}$ & $\begin{array}{c}-0.000 \\
(0.000) \\
\end{array}$ & GDP & $\begin{array}{l}0,0003 * * \\
(0.0001) \\
\end{array}$ & $\begin{array}{l}0,0005^{* * * *} \\
(0,000)\end{array}$ \\
\hline Inflation & $\begin{array}{c}0.059 \\
(0.160) \\
\end{array}$ & $\begin{array}{c}0.041 \\
(0.091) \\
\end{array}$ & Inflation & $\begin{array}{l}0,205 \\
(0,157) \\
\end{array}$ & $\begin{array}{l}0,022 \\
(0.176)\end{array}$ \\
\hline Unemployment & $\begin{array}{l}0.055 \\
(0.273)\end{array}$ & $\begin{array}{c}0.074 \\
(0.016)\end{array}$ & Unemployment & $\begin{array}{r}0,4413 \\
(0,264) \\
\end{array}$ & $\begin{array}{c}0.117 \\
(0.051) \\
\end{array}$ \\
\hline $\begin{array}{l}\text { General government } \\
\text { gross debt }\end{array}$ & $\begin{array}{c}-0.0001 \\
(0,0002)\end{array}$ & $\begin{array}{l}-0.032 \\
(0.016)\end{array}$ & $\begin{array}{l}\text { General govern- } \\
\text { ment gross debt }\end{array}$ & $\begin{array}{c}-0,0002 \\
(0,0002)\end{array}$ & $\begin{array}{c}0.004 \\
(0.032)\end{array}$ \\
\hline Doing Business & $\begin{array}{c}0.231 \\
(0.277)\end{array}$ & $\begin{array}{l}-0.203 \\
(0.124)\end{array}$ & Doing Business & $\begin{array}{c}0,635^{*} \\
(0,258)\end{array}$ & $\begin{array}{c}0.365 \\
(0.240)\end{array}$ \\
\hline $\begin{array}{l}\text { Human Freedom } \\
\text { Index }\end{array}$ & $\begin{array}{c}4.821 \\
(3.295)\end{array}$ & $\begin{array}{c}-0.349 \\
(0.976)\end{array}$ & $\begin{array}{l}\text { Human Freedom } \\
\text { Index }\end{array}$ & $\begin{array}{l}13.58^{* * * *} \\
(2.455)\end{array}$ & $\begin{array}{l}6.565 * * * \\
(1.625) \\
\end{array}$ \\
\hline Constant & $\begin{array}{l}-46.5 \\
(28.84)\end{array}$ & $\begin{array}{l}32.2 \\
(8.976)\end{array}$ & Constant & $\begin{array}{c}-110.5^{* * * *} \\
(23.06)\end{array}$ & $\begin{array}{l}-36.9 \\
(18.71)\end{array}$ \\
\hline Observations & 170 & 55 & Observations & 170 & 55 \\
\hline R Squared & 0.22 & 0.298 & R Squared & 0.87 & 0.822 \\
\hline
\end{tabular}

Note: $* \mathrm{p}<0.1, * * \mathrm{p}<0.05, * * * \mathrm{p}<0.01$.

Source: Own contribution based on data from International Monetary Fund, Transparency International and Fraser Institute.

\section{Discussion}

Our research does not prove any of the aforementioned contradictory statements about relationships between cryptocurrencies and corruption. Our results are certainly limited by certain circumstances. The number of Bitcoin ATMs in a country does not necessarily correspond to how much cryptocurrencies are prevalent in that country. Survey participants can lie and may not truthfully answer the question of whether they use or own cryptocurrencies. The relationship between Bitcoin ATMs and CPI values was examined for a larger number of countries than the relationship between corruption users and CPI. In terms of 
Bitcoin automated teller machines, the research confirms that these ATMs are only one of the ways for the inhabitants of a country to obtain cryptocurrencies. Their absence does not necessarily mean that cryptocurrencies are not used in that country. Examples include Lithuania or Sweden - countries where there is no Bitcoin ATM installed, but $8.7 \%$ and $4.4 \%$ of participants in the Bucholz (2021) survey confirmed ownership or use of cryptocurrencies. In general, for an ATM to be installed in a certain country, adequate conditions must first be created that ensure that the investment will be profitable; a high level of corruption in a country reduces the probability of return on investment. Similarly, the probability of return on investment is reduced by low GDP level, high inflation, and generally unfavourable conditions in the country (expressed by lower Doing Business and Human Freedom Index values). Consequently, the following causality is likely to apply to the relationship between the number of Bitcoin automated teller machines and corruption: too high a level of corruption prevents the installation of a Bitcoin ATM. More specifically, our research reveals that after the CPI value drops below 28, no Bitcoin ATM is installed in any country.

As regards the number of corruption users, the causality is likely to be as follows: if corruption is relatively high in a certain country, but does not exceed critical values, the situation may stimulate the use of cryptocurrencies, namely for two reasons. On one hand, cryptocurrencies can serve as a means for reducing the costs associated with corruption and increasing the anonymity of corruption-tainted contracts (see third chapter). On the other hand, even actors who do not participate in corruption in the country will strive to minimise the damage they suffered due to corruption. At least a partial transition to cryptocurrencies can offer such a solution. Their contacts become more anonymous, they are no longer subject to as much regulation, and there is less necessity to obtain the various authorisations related to the use of legal means of payment, while such authorisations can be obtained solely or more easily if the application for the authorisation is backed by a bribe. The causality described in this paragraph is confirmed by empirical data: both Bucholz surveys (Bucholz, 2019; 2021) reveal that almost all the top 10 countries with the most cryptocurrency users have CPI values between 33 and 40 and their medians are approximately 37 (see Table 2). In other words, these countries do not rank among the most corrupt, yet corruption is largely widespread there. Our results can be linked to those of Johnson (2020), who revealed that that the price paid for Bitcoin above market price goes hand-in-hand with the level of corruption. As corruption increases, so does the premium paid for Bitcoin. This finding indicates that people from countries with high levels of corruption try to obtain Bitcoin and use it either as the means of a corruption transaction or as protection against the impacts of corruption. But at least the basic conditions must be created so that cryptocurrencies can be used. 
Table 2

Corruption Perception Index (CPI) Values for the Top 10 Countries with the Highest Number of Cryptocurrency Users or Owners

\begin{tabular}{|c|c|c|c|c|c|}
\hline \multicolumn{3}{|c|}{2021 Survey } & \multicolumn{3}{|c|}{2019 Survey } \\
\hline Country & Cryptocurrency (1) & $C P I$ & Country & Cryptocurrency (1) & $C P I$ \\
\hline Nigeria & 31.9 & 34.00 & Nigeria & 28 & 34.00 \\
\hline Vietnam & 21.1 & 35.00 & Thailand & 23 & 36.00 \\
\hline Philippines & 19.8 & 35.00 & Vietnam & 22 & 33.66 \\
\hline South Africa & 17.8 & 43.66 & Turkey & 20 & 40.66 \\
\hline Thailand & 17.6 & 36.00 & Brazil & 18 & 37.33 \\
\hline Peru & 16.1 & 36.33 & Columbia & 18 & 37.00 \\
\hline Turkey & 16.1 & 40.00 & Argentina & 16 & 38.33 \\
\hline Colombia & 15.3 & 37.00 & South Africa & 16 & 43.66 \\
\hline Argentina & 14.4 & 41.00 & Peru & 15 & 35.66 \\
\hline Indonesia & 13.0 & 38.33 & Saudi Arabia & 14 & 48.00 \\
\hline Median & & 36.67 & Median & & 37.83 \\
\hline
\end{tabular}

Note: (1) The number in the column refers to the percent of cryptocurrency users or owners out of total respondents.

Source: Own research based on Bucholz (2019; 2021).

\section{Conclusion}

In this paper, we presented cryptocurrencies and their characteristics. When the relevant transactions are carried out in a convenient manner, cryptocurrencies can reach a high level of anonymity where it is virtually impossible to identify the persons participating in the cryptocurrency transaction. On the contrary, when it is used without prudence, cryptocurrency transactions are fully transparent. Our aim was to examine the relationship between the level of corruption and the extent to which cryptocurrencies are widespread. To this end, we presented four scenarios in the third chapter showing how cryptocurrencies could possibly be used for corruption. The different scenarios vary in the level of competence in cryptocurrencies required of their participants. Regardless of the required competence, the scenarios imply that cryptocurrencies reduce the transaction costs and risks of corruption-tainted contracts. They allow, in particular, for the anonymous transfer of corruption-based consideration (benefits) provided by the corrupting agent to the corrupt agent and, at the same time, expand the range of possible types of payment that can be provided by the corrupting agent. As a result of their anonymity and relatively easy transfer, cryptocurrencies reduce the need for a personal meeting between the corrupting agent and the corrupt agent to hand over the corruption-based consideration. Other forms of non-personal contact between a corrupting agent and a corrupt agent (e.g., transferring corruption-based consideration to a bank account, sending corruption-based consideration or benefits through an intermediary) are riskier. Using cryptocurrencies, actors potentially interested in a corruption-tainted contract can more easily seek 
a counterparty with whom they will not be directly in contact. Corruption can thus also emerge in fields where it has not hitherto been advantageous due to the costs and risks.

The fourth chapter examined the empirical relationships between corruption and cryptocurrencies in various countries. We did not find any general causality between proxies represented both variables, but we revealed that no Bitcoin ATM is installed in a country with a CPI value of less than 28 and that the first ten countries with the most cryptocurrency users or owners have a CPI value typically ranging between 33 and 40, and thus rank among countries with relatively high corruption, however the level of corruption does not exceed a critical threshold (probably around 30 points of CPI index). Our research indicates that where corruption reaches a significantly high value, the country does not have sufficient technical and legal conditions for more people to use cryptocurrencies. On the other hand, such conditions still exist in in countries with CPI values between 33 and 40, and the citizens of these countries most likely use cryptocurrencies both as a means for carrying out corruption transactions and as protection for mitigating the consequences of corruption.

It is essential to point out that cryptocurrencies in particular are part of a rapidly evolving world and that our results, which are based on data to May 2021, might not be permanently valid. It is therefore advisable to continue to monitor the relationship between cryptocurrencies and corruption in the future and find other means to express this relationship. It is particularly desirable to obtain more data as to how widespread cryptocurrencies are in different countries. Our paper can serve as a basis for further empirical examinations, including the confirmation or refutation of our data and conclusions.

\section{References}

AIDT, T. S. (2016): Rent-seeking and Economics of Corruption. Constitutional Political Economy, 27, No. 2, pp. $142-157$.

ALBRECHT, C. - McKAY DUFFIN, K. - HAWKINS, S. - MORALES ROCHA, V. M. (2019): The Use of Cryptocurrencies in the Money Laundering Process. Journal of Money Laundering Control, 22, No. 2, pp. $210-216$.

ALDAZ-CARROLL, E. - ALDAZ-CARROLL, E. (2018): Can Cryptocurrencies and Blockchain Help Fight Corruption? Washington, DC: Brooking Institute. [Cit. $25^{\text {th }}$ May 2021.] Available at: $<$ https://www.brookings.edu/blog/future-development/2018/02/01/can-cryptocurrencies-andblockchain-help-fight-corruption/>.

ANTONOPOULOS, A. M. (2017): Mastering Bitcoin. Second Edition. Sebastopol: O'Reilly Media, Inc. ISBN 978-1491954386.

BESHARAT, S. (2019): Challenges Application of Bitcoin. Dilemas Contemporáneos: Educación, Política y Valore, 6, No. 2, pp. 1 - 27. 
BERG, A. - MARKEY-TOWLER, B. - NOVAK, M. (2020): Blockchains: Less Government, More Market. The Journal of Private Enterprise, 35, No. 2, pp. 1 - 21. Available at: $<$ http://dx.doi.org/10.2139/ssrn.3301714>.

BLOCKCHAIN LUXEMBOURG (2009): Bitcoin Blocks at Height 1. [Cit. 25 ${ }^{\text {th }}$ May 2021.] Available at: <https://www.blockchain.com/btc/block-height/1>.

BUCHOLZ, K. (2019): How Common is Crypto? New York: Statista. [Cit. 25 ${ }^{\text {th }}$ May 2021.] Available at: <https://www.statista.com/chart/18345/crypto-currency-adoption/>.

BUCHOLZ, K. (2021): How Common is Crypto? New York: Statista. [Cit. $25^{\text {th }}$ May 2021.] Available at: 〈https://www.statista.com/chart/18345/crypto-currency-adoption/>.

CAMPOS, N. F. - DIMOVA, R. - SALEH, A. (2016): Corruption and Economic Growth: An Econometric Survey of the Evidence. Journal of Institutional and Theoretical Economics, 172, No. 3, pp. 521 - 543. Available at: 〈http://dx.doi.org/10.1628/093245616X14616712130543>.

CAMPBELL-VERDUYN, M. (2018): Bitcoin, Crypto-Coins, and Global Anti-Money Laundering Governance. Crime, Law and Social Change, 69, No. 2, pp. 283 - 305. Available at: <http://dx.doi.org/10.1007/s10611-017-9756-5>.

CIUPA, K. (2019): Cryptocurrencies: Opportunities, Risks and Challenges for Anti-Corruption Compliance System. Paris: OECD. [Cit. 25 ${ }^{\text {th }}$ May 2021.] Available at:

$<$ https://www.oecd.org/corruption/integrity-forum/academic-papers/Ciupa-Katarzynacryptocurrencies.pdf/>.

CLARK, J. (2016): Preface - The Long Road to Bitcoin. In: NARAYANAN, A., BONNEAU, J., FELTEN, E., MILLER, A. and GOLDFEDER, S. (eds.): Bitcoin and Cryptocurrency Technologies. Princeton: Princeton University Press, pp. 3 - 21.

COINMARKETCAP (2021): Cryptocurrency Market Capitalizations. [Cit. 25 $5^{\text {th }}$ May 2021]. Available at: <https://coinmarketcap.com/>.

DABROWSKI, M. - JANIKOWSKI, L. (2018): Virtual Currencies and Their Potential Impact on Financial Markets and Monetary Policy. [CASE Network Studies and Analyses, No. 495.] Warsaw: CASE. ISBN 978-8371786730. [Cit. 25 ${ }^{\text {th }}$ May 2021.] Available at: <http://www.case-research.eu/files/?id_plik=5708>.

DUDLEY, S. - POND, T. - CARDEN, S. (2019): Evasive Maneuvers How Malign Actors Leverage Cryptocurrency. Washington, DC: National Defence University. [Cit. 25 ${ }^{\text {th }}$ May 2021.] Available at: <https://ndupress.ndu.edu/Portals/68/Documents/jfq/jfq-92/jfq-92_58-64_Dudley-et-al.pdf>.

DESHWAI, M. - SINGH KAURAV, R. P. - THAKUR, K. S. (2019): Cryptocurrency Technology: Prospects in the Success of Different Organizations. [Proceedings of 10th International Conference on Digital Strategies for Organizational Success.] [Cit. $25^{\text {th }}$ May 2021.] Available at: <https://papers.ssrn.com/sol3/papers.cfm?abstract_id=3323865>.

EUROPEAN BANKING AUTHORITY (2014): EBA Opinion on Virtual Currencies (EBA/Op/ 2014/08). [Cit. 25 ${ }^{\text {th }}$ May 2021.] Available at: <https://eba.europa.eu/documents/10180/657547/EBA-Op-201408+Opinion+on+Virtual+Currencies.pdf $>$.

EUROPEAN BANKING AUTHORITY (2019): Report with Advice for the European Commission on Crypto-assets. [EBA Report 9 January 2019.] [Cit. $25^{\text {th }}$ May 2021.] Available at: <https://eba.europa.eu/documents/10180/2545547/EBA+Report+on+crypto+assets.pdf>.

FERRIS, S. (2018): The Blockchain Brief. Journal of Government Financial Management, 67, No. 4, pp. $24-29$.

FOLEY, S. - KARLSEN, J. R. - PUTNINS, T. J. (2018): Sex, Drugs, and Bitcoin: How Much Illegal Activity is Financed through Cryptocurrencies? Rochester, NY: SSRN. [Cit. $25^{\text {th }}$ May 2021.] Available at: <https://papers.ssrn.com/sol3/papers.cfm?abstract_id=3102645>.

GONG, T. (2002): Dangerous Collusion: Corruption as a Collective Venture in Contemporary China. Communist Post-Communist Studies, 35, No. 1, pp. 85 - 103. Available at: <http://dx.doi.org/10.1016/S0967-067X(01)00026-5>. 
CHARRON, N. (2016): Do Corruption Measures Have a Perception Problem? Assessing the Relationship between Experiences and Perceptions of Corruption among Citizens and Experts. European Political Science Review, 8, No. 1, pp. 147 - 171. Available at: <http://dx.doi.org/10.1017/S1755773914000447>.

JOHNSON, J. (2020): Bitcoin, Corruption and Economic Freedom. Journal of Financial Crime, 27, No. 1, pp. 58 - 66. DOI: 10.1108/JFC-11-2018-0122.

KATONA, V. (2018): Can Blockchain Bring an End to Corruption? Daily News, Beirut, $4^{\text {th }}$ January 2018. [Cit. 25 ${ }^{\text {th }}$ May 2021.] Available at: <https://www.yerepouni-news.com/2018/01/04/can-blockchain-bring-an-end-to-corruption>.

KLITGAARD, R. (1988): Controlling Corruption. Berkeley: University of California Press. ISBN 978-0520074088.

KONASHEVYCH, O. (2017): The Concept of the Blockchain-Based Governing: Current Issues and General Vision. [17th European Conference on Digital Government.] Berlin: ResearchGate. [Cit. 25 ${ }^{\text {th }}$ May 2021.] Available at: <https://www.researchgate.net/publication/330106495_The_Concept_of_the_BlockchainBased_Governing_Current_Issues_and_General_Vision>.

LAMBSDORFF, J. G. (2007): The Institutional Economics of Corruption and Reform: Theory, Evidence and Police. Cambridge, UK: Cambridge University Press. ISBN 0521872758.

LÁNSKY, J. (2018a): Possible State Approaches to Cryptocurrencies. Journal of Systems Integration, 9, No. 1, pp. 19 - 31. Available at: 〈http://dx.doi.org/10.20470/jsi.v9i1.335〉.

LÁNSKY, J. (2018b): Kryptoměny. Praha: C.H.Beck. ISBN 978-8074007224.

LÁNSKY, J. (2020): Cryptocurrency Survival Analysis. The Journal of Alternative Investments, 22, No. 3, pp. 55 - 64. Available at: 〈http://dx.doi.org/10.3905/jai.2019.1.084>.

LOVELL, A. M. (2019): Avoiding Liability: Changing the Regulatory Structure of Cryptocurrencies to Better Ensure Legal Use. Iowa Law Review, 104, No. 2, pp. 927 - 955.

MACKEY, T. K. - CUOMO, R. E. (2020): An Interdisciplinary Review of Digital Technologies to Facilitate Anti-Corruption, Transparency and Accountability in Medicines Procurement. Global Health Action, 13, No. 1 (Supplement), pp. 1 - 13. Available at: <https://doi.org/10.1080/16549716.2019.1695241>.

MUNGIU-PIPPIDI, A. - HEYWOOD, P. M. (2020): Research Agenda for Studies of Corruption. Northampton: Edward Elgar Publishing.

NAKAMOTO, S. (2008): A Peer-to-Peer Electronic Cash System. No town and publisher mentioned. [Cit. 25 ${ }^{\text {th }}$ May 2021]. Available at: 〈https://bitcoin.org/bitcoin.pdf〉.

NICKERSON, M. A. (2019): Fraud in a World of Advanced Technologies: The Possibilities are (Unfortunately) Endless. The CPA Journal, 89, No. 6, pp. 28 - 34.

OSIPIAN, A. L. (2013): Corrupt Organizations: Modeling Educators' Misconduct with Cellular Automata. Computational and Mathematical Organization Theory, 19, No. 1, pp. $1-24$. Available at: 〈http://dx.doi.org/10.1007/s10588-012-9120-3>.

OSRECKI, F. (2015): Fighting Corruption with Transparent Organizations: Anti-Corruption and Functional Deviance in Organizational Behavior. Ephemera, 15, No. 2, pp. 337 - 364.

ROSE-ACKERMAN, S. - PALIFKA, B. J. (2016): Corruption and Government: Causes, Consequences and Reform. Cambridge, UK: Cambridge University Press. ISBN 978-1107441095.

SAYED, M. N. - ABBAS, N. A. (2018): Impact of Crypto-currency on Emerging Market Focus on Gulf Countries. Life Science Journal, 15, No. 1, pp. 92 - 97. DOI: 10.7537/marslsj150118.16.

SCHRÖDINGER, E. (1935): Die gegenwärtige Situation in der Quantenmechanik. [The Present Situation in Quantum Mechanics.] Naturwissenschaften, 23, No. 48, pp. 807 - 812. Available at: <https://doi.org/10.1007/BF01491891>.

SERHACK (2018): Mastering Monero: The Future of Private Transactions. Independently Published. ISBN 978-1731079961.

SLADIČ, Z. - MILOSAVLJEVIČ, B. - NIKOLIČ, S. - SLADIČ, D. - RADULOVIČ. A. (2020): A Blockchain Solution for Securing Real Property Transactions: A Case Study for Serbia. ISPRS - International Journal of Geo-Information, 10, No. 35, pp. 1 - 22. Available at: <https://doi.org/10.3390/ijgi10010035>. 
STADDON, J. (2017): Scientific Method: How Science Works, Fails to Work, and Pretends to Work. London: Routledge. ISBN 978113829536.

De SOUZA, R. C. - LUCIANO, E. M. - WIEDENHÖFT, G. C. (2018): The Uses of the Blockchain Smart Contracts to Reduce the Levels of Corruption: Some Preliminary Thoughts. Berlin: ResearchGate. Available at:

<https://www.researchgate.net/publication/325495539_The_uses_of_the_blockchain_smart_co ntracts_to_reduce_the_levels_of_corruption_some_preliminary_thoughts $>$.

ŠIMONOVÁ, J. - ČENTÉŠ, J. - BELEŠ, A. (2020): Financial Analysis of Innovative Forms of Money. Entrepreneurship and Sustainability Issues, 7, No. 1, pp. $69-80$. Available at: <http://doi.org/10.9770/jesi.2019.7.1(6)>.

WAWROSZ, P. (2019): Productive of the Service Sector: Theory and Practice of Corruption Declining. Marketing and Management of Innovation, 10, No. 4, pp. 269 - 279. Available at: <http://dx.doi.org/10.21272/mmi.2019.4-21>. 